\title{
A ESCRITA COMO RECURSO MNEMÔNICO NA FASE INICIAL DE ALFABETIZAÇÃO ESCOLAR: UMA ANÁLISE HISTÓRICO-CULTURAL
}

\author{
Cláudia Maria Mendes Gontijo* \\ SÉrgio ANTÔNIO da SiLVA Leite**
}

\begin{abstract}
RESUMO: Com base na concepção de que a linguagem escrita é um sistema de signos que serve como apoio às funções intelectuais, o artigo apresenta os resultados da pesquisa cuja finalidade foi investigar os processos que se constituem nas crianças, na fase inicial de alfabetização escolar, ao serem incentivadas a usar a escrita como recurso mnemônico. A partir das atividades de registro dos textos, elaborados oralmente pelas crianças, conclui que o surgimento de grafias indiferenciadas propiciadas pela presença, nos textos, de quantidades, palavras que se repetiam e palavras cuja grafia as crianças dominavam, possibilitou que os alunos estabelecessem uma relação funcional com a escrita e, portanto, a usasse como recurso mnemônico.
\end{abstract}

Palavras-chave: Alfabetização. Escrita. Recurso mnemônico.

\section{WRITING AS A MNEMONIC RESOURCE DURING THE INITIAL PHASE OF SCHOOLING: A HISTORICAL-CULTURAL ANALYSIS}

ABSTRACT: Based on the conception that written language is a system of signs that supports the intellectual functions, this paper presents the results of a research aimed at investigating the processes that build up in children during the initial phase of their learning to read and write, at school, when encouraged to use writing as a mnemonic resource. From activities involving registration of texts orally produced by the children, we can conclude that the uprising of indifferentiated spellings due to the presence, in the texts, of quantities, words which are repeated and which the children are familiar to the spelling, made it possible for the students to establish a functional relation to writing and therefore employ it as a nmeumonic resource.

Key words: Learning to read and write. Writing. Mnemonic resource.

\footnotetext{
* Professora da Universidade Federal de São Carlos (UfSCAR) e Universidade Federal do Espírito Santo (UFES). E-mail: cmmg@power.ufscar.br

** $\quad$ Membro do Grupo de Pesquisa Alfabetização, Leitura e Escrita (Alle), da Faculdade de Educação da Unicamp. E-mail: saleite@uol.com.br
} 
7 partir da década de 1980, com a divulgação, no Brasil, dos estudos de Ferreiro \& Teberosky sobre a gênese da leitura e da escrita, as concepções tradicionais de alfabetização, baseadas na visão de que a aprendizagem da linguagem escrita é um processo de associação de símbolos gráficos a sons da fala e, por isso, um processo mecânico de repetição de letras ou sílabas e seus respectivos segmentos sonoros, passaram a ser questionadas com mais intensidade.

A crise histórica da Psicologia, principalmente da objetivista, e o reiterado fracasso escolar das crianças de escolas públicas na fase inicial de alfabetização contribuíram para que a teoria de Ferreiro \& Teberosky (1989), orientada para pressupostos interacionistas, na perspectiva psicogenética, encontrasse campo fértil para divulgação e aceitação no meio educacional. As próprias pesquisadoras assinalaram que as elaborações que construíram eram as primeiras no sentido de "proceder a uma revisão completa de nossas idéias sobre a aprendizagem da língua escrita, a partir das descobertas da psicolingüística contemporânea” (p. 25 ) e as primeiras a vincular esses conhecimentos "com o desenvolvimento cognitivo, tal como é visto na teoria de Piaget” (p. 25).

Além disso, apontam que essa nova forma de conceber a alfabetização, considerando o sujeito que aprende e, portanto, a sua atividade, tem "como fim último o de contribuir na solução dos problemas de aprendizagem da lecto-escritura na América Latina, e o de evitar que o sistema educacional continue produzindo futuros analfabetos" (Ferreiro \& Teberosky, 1989, p. 32). Entretanto, as expectativas de resolver os problemas denominados por Ferreiro \& Teberosky (1989) de seleção social e expulsão encoberta, gerados pela distribuição desigual de oportunidades educacionais, não se concretizaram e muitas crianças que são matriculadas nas escolas continuam sem aprender a ler e a escrever, porque a solução para o problema do fracasso escolar, durante a alfabetização, exige não apenas mudanças nas concepções de ensino e aprendizagem, mas demanda, sobretudo, empenho e vontade dos Poderes Públicos no sentido de garantirem as condições para que o sistema educacional possibilite a efetiva aprendizagem.

No entanto, é evidente que não podemos deixar de ressaltar a contribuição da teoria psicogenética de aprendizagem da leitura e da escrita, uma vez que essa teoria contribuiu para romper as concepções tradicionais de alfabetização e possibilitou que os professores alfabetizadores começassem a refletir sobre a participação da criança no processo de aprendizagem e sobre o trabalho que realizavam para ensinar as crianças a ler e a escrever. 
O estudo que realizamos sobre a apropriação da linguagem escrita pelas crianças, em fase inicial de alfabetização, pretende contribuir com as reflexões em torno desse processo, por meio de uma análise que leva em conta os pressupostos da Perspectiva Histórico-Cultural na Psicologia. Dessa forma, concordando com esses pressupostos, assumimos que a alfabetização é um processo histórico e social de formação, nas crianças,
da linguagem escrita.

Sabemos que os fundamentos que norteiam os estudos de Ferreiro \& Teberosky (1989) são notadamente construtivistas. Esta

(...) é uma concepção ou uma teoria que privilegia a noção de "construção" de conhecimento, efetuada mediante interações (grifo nosso) entre o SUJEITO (aquele que conhece) e OBJETO (sua fonte de conhecimento) - buscando superar as concepções que focalizam apenas o empirismo (...) ou a pré-formação de estruturas (...). (Bregunci, 199?, p. 15)

Assim, a principal categoria que orienta os estudos com pressupostos construtivistas é o interacionismo, que implica as noções de adaptação e de equilíbrio da relação entre o organismo e o meio. Do ponto de vista da Perspectiva Histórico-Cultural na Psicologia, o modelo interacionista não possibilita "a compreensão da relação histórico-social entre objetivação e apropriação que caracteriza a especificidade do desenvolvimento humano tanto do ponto de vista do gênero humano quanto do indivíduo" (Duarte, 1993, p. 108).

Consideramos que a formação nos indivíduos dos resultados do desenvolvimento histórico e social se realiza por intermédio de mediações entre o indivíduo e o gênero bumano, sendo essas mediações exteriores ao organismo e não resultado da herança genética. Por isso, a análise que realizamos do processo de alfabetização levou em conta o processo de apropriação, pois as crianças não se adaptam à linguagem escrita, mas apropriam-se dela. Elas tomam para si esse conhecimento e a prática educativa da alfabetização é mediadora desse processo. De acordo com Leontiev, "a diferença fundamental entre os processos de adaptação em sentido próprio e os de apropriação reside no fato de o processo de adaptação biológica transformar (grifo do autor) as propriedades e faculdades específicas do organismo bem como o seu comportamento de espécie” (1978, p. 169). O processo de apropriação é diferente, pois “o seu resultado é a reprodução (grifo do autor), pelo indivíduo, das aptidões e funções humanas, historicamente formadas” (p. 169). Assim, é por meio do processo da apropriação que os indivíduos tornam seus os resultados do desenvolvimento sócio-histórico da humanidade e, portanto, a linguagem escrita. 
Luria (1988) descreveu, no seu trabalho sobre o desenvolvimento da escrita, como as crianças que não estavam participando de um processo escolar de alfabetização passaram a usar sinais, marcas e desenhos como símbolos, pois estes adquirem um significado funcional e começam a refletir o conteúdo registrado. Esse autor diz que o período primitivo por ele estudado chega ao fim quando a criança inicia o processo de escolarização e indica que, entre o período de elaboração das primeiras formas simbólicas de representação e a elaboração da escrita na sua forma cultural, existe um longo período, particularmente interessante para a pesquisa psicológica.

Interessado por esse período, Luria (1988) descreveu alguns dados de pesquisa coletados com crianças que conheciam algumas letras do alfabeto, mas que ainda não podiam escrever convencionalmente usando as letras conhecidas. Com base nesses dados e no estudo sobre a prébistória da escrita, afirmou que

(...) a escrita não se desenvolve, de forma alguma, em uma linha reta, com um crescimento e aperfeiçoamento contínuos. Como qualquer outra função psicológica cultural, o desenvolvimento da escrita depende, em considerável extensão, das técnicas de escrita usadas e equivale essencialmente à substituição [grifo nosso] de uma técnica por outra. (Luria, 1988, p. 180)

Centraremos, inicialmente, nossas ponderações na primeira parte da citação: entendemos que Luria considerava que a criança, antes de participar de um processo escolar de alfabetização, compreende que pode usar sinais, marcas, desenhos etc. como símbolos, pois estes passam a expressar significados que ela desejou registrar, mas isso não a habilita a utilizar esses conhecimentos quando é exposta às formas culturais de escrita, ou seja, quando começa a aprender, na escola, o sistema de escrita utilizado socialmente. Para o autor, é exatamente a substituição de uma técnica por outra que leva a um aprimoramento das habilidades de ler e escrever. Porém, a aprendizagem de uma nova forma de escrita "inicialmente atrasa, de forma considerável, o processo de escrita, após o que então ele se desenvolve mais até um nível novo e mais elevado" (Luria, 1988, p. 180).

Assim, para Luria, as crianças iniciam o desenvolvimento da escrita mesmo antes de estarem expostas a um processo escolar de aprendizagem da linguagem escrita. Esse período, anterior à aprendizagem escolar, é denominado de pré-história da escrita e é constituído por estágios que podem, de maneira geral, ser traduzidos pela seguinte explicação:

No começo, a criança relaciona-se com coisas escritas sem compreender o significado da escrita; no primeiro estágio, escrever não é um meio de registrar algum 
conteúdo específico, mas um processo autocontido, que envolve a imitação de uma atividade do adulto, mas que não possui, em si mesmo, significado funcional. Esta fase é caracterizada por rabiscos não-diferenciados; a criança registra qualquer idéia com exatamente os mesmos rabiscos. Mais tarde - e vimos como se desenvolve - começa a diferenciação: o símbolo adquire um significado funcional e começa graficamente a refletir o conteúdo que a criança deve anotar. (Luria, 1988, p. 181)

Ao iniciar o processo de escolarização, a criança é exposta sistematicamente à aprendizagem de um novo sistema de escrita, utilizado socialmente. Tendo que utilizar essa nova forma de escrita, Luria acredita que as crianças passam pela mesma fase primitiva, ou seja, retomam uma escrita indiferenciada. Nesse sentido, o desenvolvimento da escrita não é um processo linear e de contínuo aperfeiçoamento e a aprendizagem de uma nova forma de escrita pode propiciar o retorno às formas primárias de as crianças se relacionarem com os registros.

Concordamos com o autor: de fato, no início da alfabetização escolar, as crianças escrevem utilizando as letras que estão sendo aprendidas, mas ainda não conseguem estabelecer uma relação funcional com elas. Ainda de acordo com Luria (1988), o desenvolvimento da escrita é dependente da substituição ${ }^{1}$ de uma técnica de escrita por outra. Conforme nosso entendimento, o autor refere-se a duas técnicas de escrita: uma elaborada pela criança pré-escolar, que se caracteriza pelo uso de sinais, marcas, pontos, desenhos etc. como símbolos que possibilitam a recordação de significados anotados - essa é uma forma primitiva de registro, pois possui um caráter espontâneo, pré-bistórico, independente das aprendizagens que são elaboradas na escola; a outra equivale às formas culturais, ou seja, ao sistema de escrita elaborado ao longo da história social e que depende de uma ação sistemática e intencional para que as crianças venham a se apropriar dessas formas.

Interessados pela apropriação das formas culturais de escrita aprendidas na escola, consideramos fundamental no artigo elaborado por Luria a indicação de que, a partir "do momento em que uma criança começa, pela primeira vez, a aprender a escrever até a hora que finalmente domina essa habilidade, há um longo período, particularmente interessante para a pesquisa psicológica” (p. 180). Visando a contribuir para a compreensão dos processos que se constituem na criança, nesse período, o estudo que realizamos sobre o processo de apropriação da linguagem escrita em crianças na fase inicial de alfabetização escolar teve por finalidade investigar como as crianças escrevem e se relacionam com a linguagem escrita ao serem incentivadas a utilizá-la como recurso 
mnemônico. Desse modo, partimos do princípio de que a linguagem escrita é um sistema de signos que serve de apoio às funções intelectuais, especificamente à memória.

Escolhemos para participar da pesquisa 39 crianças matriculadas na primeira série do ensino fundamental, da rede pública de ensino, pois sabemos que a maioria utiliza as letras do alfabeto para escrever, mas não as utiliza convencionalmente. Tendo por base o objetivo do estudo, foi necessário planejar atividades de produção de textos para serem realizadas pelas crianças. Essas atividades consistiram na produção oral de textos pelas crianças e do seu registro pelos pesquisadores. Em seguida, as próprias crianças registravam os textos produzidos oralmente e, ao final, eram incentivadas a usar os registros para lembrar o texto que motivou a escrita. Essas atividades ocorreram em cinco momentos do ano letivo: no primeiro momento, as crianças registraram um texto sobre sua brincadeira preferida; no segundo, registraram o reconto oral da história de autoria de Ruth Rocha, Marcelo, marmelo, martelo; no terceiro, registraram um poema previamente escolhido; no quarto, escreveram um texto sobre $A$ escola; e, no quinto momento, escreveram uma história com base em duas histórias em seqüência ("O pirulito" e "O telefone") do livro $O$ amigo da bruxinha, de Eva Furnari. Com base nas atividades realizadas pelas crianças, observamos que: 1) havia crianças que não utilizavam a escrita como recurso para lembrar os significados anotados; 2) outras utilizavam a escrita como recurso mnemônico.

\section{As crianças não utilizavam a escrita como recurso para lembrar os} significados anotados

Verificamos, com base nas atividades realizadas, que as crianças que não utilizavam a escrita para lembrar o texto que motivou o registro produziam: a) grafias indiferenciadas; b) diferenciavam os registros para escrever os enunciados do texto ou; c) relacionavam as letras anotadas com as unidades constituintes da linguagem oral.

\section{a) As indiferenciações na escrita}

Ao iniciar o processo de escolarização, a criança é exposta sistematicamente à aprendizagem de um novo sistema de escrita, utilizado socialmente. Assim, segundo Luria (1988), a criança que já aprendeu as letras do alfabeto compreende que pode usar signos para escrever, mas não entende ainda como fazê-lo. Por isso, "começa com uma fase de escrita não diferenciada pela qual já passara muito antes” (p. 181). 
Observamos, durante o estudo, que uma das crianças (Laudicéia) escreveu o reconto da história Marcelo, marmelo, martelo com grafias quase totalmente indiferenciadas. Vejamos a escrita elaborada pela aluna. ${ }^{2}$ Ela estava com 7 anos e 7 meses de idade.

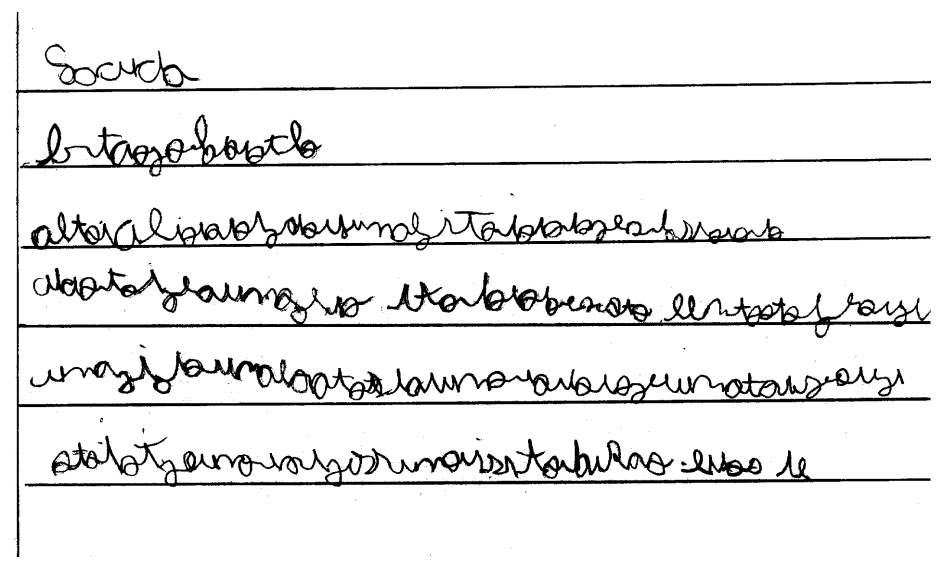

\section{Marcelo, marmelo, martelo}

Uma pessoa jogou cigarro na casa do cachorro.

Marcelo foi contar para seu pai,

mas o pai não entendeu o que Marcelo dizia. Depois, o pai prometeu que iria construir uma casa nova para o cachorro.

Laudicéia permaneceu, durante todo o ano em que realizamos o estudo, usando as mesmas grafias para escrever os textos e era interessante observar durante os registros que, para cada enunciado do texto, escrevia uma linha com essas grafias, murmurava palavras inaudíveis e, ao final, ao ser incentivada a lembrar o texto, apontava as grafias anotadas. Sabemos que não utilizava a escrita como recurso mnemônico, mas suas ações retratavam as atitudes dos adultos ao escreverem. Assim, conforme Luria (1988), a natureza indiferenciada da escrita revela que a criança ainda não compreendeu que a escrita pode ajudá-la na recordação dos significados anotados e, por isso, rememorou o texto.

O fato de a criança usar, durante todo o ano, grafias indiferenciadas para anotar os textos impossibilita que façamos pressuposições quanto ao que pode ocorrer com essa criança, mesmo porque todos os outros sujeitos que participaram da pesquisa diferenciavam a escrita ao escreverem os textos. Até mesmo uma criança (Jéssica Fernanda) que conciliou os desenhos e as letras para registrar o texto sobre a sua brincadeira preferida 
diferenciou os segmentos de letras utilizados para escrevê-lo. Dessa forma, a escrita produzida por Laudicéia é simbólica, pois representou os enunciados dos textos por meio de símbolos arbitrários. Entretanto, esses símbolos não possibilitaram que a criança lembrasse o texto que motivou os registros e, por isso, não atuaram com recurso mnemônico.

\section{b) Diferenciações na escrita}

As crianças que utilizavam letras para escrever e não tinham o domínio da escrita alfabética diferenciavam a escrita para escrever os enunciados do texto que produziram oralmente. Contudo, as distinções nos registros não possibilitaram a emergência da escrita significativa, ou seja, não propiciaram que as crianças utilizassem a escrita para lembrar. Luria (1988), contrariamente, notou que as diferenciações nos registros, propiciadas pela introdução de determinados fatores no conteúdo das frases e palavras que eram escritas, possibilitaram a emergência de grafias significativas, pois estas passaram a refletir os significados que a criança desejou anotar.

Esse autor cita, no seu trabalho, o exemplo de uma criança (Shura I.) que combinava a pictografia com marcas que denominou de escrita simbólica arbitrária, ${ }^{3}$ pois não expressava diretamente o conteúdo registrado. Durante o estudo que realizamos, observamos uma criança que utilizou letras e desenhos para grafar alguns dos enunciados do texto produzido oralmente. Essa criança (Jéssica Fernanda) escrevia a explicação de como é desenhada a Amarelinha. A explicação envolvia a escrita de formas e tamanhos (quadrados grandes, pequenos, quadradinhos) e, por isso, acreditamos que a criança utilizou, também, a pictografia para escrever o texto. Analisemos a sua escrita. Jéssica Fernanda tinha 6 anos e 11 meses de idade.

\section{JÉSSKKA FERNANDA}

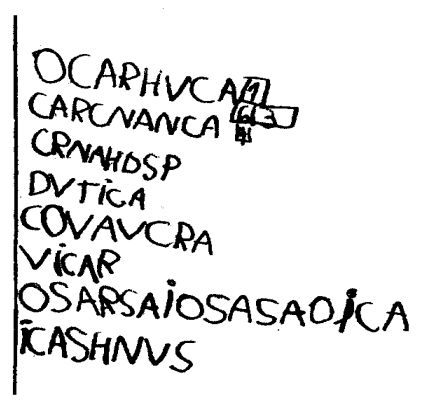

\section{CARCÃo}




\section{Amarelinha}

Coloca um quadradinho e faz o número um.

Coloca um quadradrão perto do número um

e, depois, coloca um risco no meio.

Coloca o dois de um lado e o três do outro.

Depois, faz um quadradinho pequeno e escreve o quatro.

Faz outro quadradão e coloca o cinco e o seis.

Faz um quadradinho e coloca o sete.

Coloca um quadradão e coloca os números oito e nove.

Faz um quadradinho pequeno e coloca o número dez.

Como pode ser visto, as letras grafadas para cada enunciado do texto eram diferenciadas e, dessa forma, constatamos que a criança havia compreendido que, para registrar significados diferentes, eram necessárias distinções na escrita. Ela lembrou um texto muito próximo daquele que motivou o registro. As partes lembradas seguiram a ordem dos registros. Certamente a lembrança foi motivada pelos desenhos, mas sabemos que a criança sabia o texto de memória e, como registrou um segmento de grafias para cada parte do texto, foi suficiente repetir o texto que sabia de cor e apontar cada segmento. Portanto, nessas condições, não podemos dizer que ela utilizava os símbolos alfabéticos para fins mnemônicos.

O fato de a criança ter utilizado letras e desenhos para escrever o texto não significa que não compreendia as distinções entre as formas icônicas e as não-icônicas de representação. Ela compreendia; tanto que, no início do registro, perguntou se deveria desenhar ou escrever, ao que respondemos que deveria escrever. Acreditamos que os fatores (formas e tamanhos) presentes no conteúdo do texto foram determinantes para que a criança escolhesse, também, o desenho para registrar a explicação da brincadeira. Isto é, quando as crianças utilizam as letras do alfabeto para escrever, tais fatores, presentes no conteúdo do texto, propiciam o retorno às primeiras formas de escrita significativa.

Por outro lado, a atividade realizada pela criança é muito importante para colocar em evidência que a utilização de letras para escrever, e, portanto, a compreensão das distinções entre os modos icônico e nãoicônico de representação, nem sempre é seguida pela utilização de escritas não diferenciadas. A criança distinguia as cadeias de letras utilizadas para registrar cada enunciado do texto e variava as letras numa mesma cadeia. Como o próprio Luria (1988) afirmou, as crianças, sob certas condições, podem apresentar formas diversificadas de ação na atividade de registro, o que resulta em uma grande dificuldade de estabelecer, para a apropriação da escrita, um processo evolutivo linear e de constante aperfeiçoamento. 
Isso aponta um dos pressupostos essenciais da visão que norteia os estudos na Perspectiva Histórico-Cultural que afirma a atividade dos indivíduos diante das produções humanas, ou seja, a apropriação da linguagem escrita é, também, obra da criança que se desenvolve. Vigotski (1987) estava certo ao afirmar que, se quisermos captar as particularidades do desenvolvimento infantil em toda a sua complexidade e riqueza, é necessária uma mudança radical nas concepções de desenvolvimento que fundamentam os estudos psicológicos. Para o autor, o desenvolvimento

(...) é um processo dialético complexo que se caracteriza por uma periodicidade múltipla, por uma desproporção no desenvolvimento das distintas funções, por metamorfoses ou transformações qualitativas de umas formas em outras, pelo complicado entrecruzamento dos processos de evolução e involução, pela relação entre fatores internos e externos e pelo intricado processo de superação das dificuldades e de adaptação. (1987, p. 151) [Tradução nossa].

Como dissemos, Luria notou que as diferenciações nos registros, propiciadas pela introdução de determinados fatores (cor, tamanho, forma, quantidade etc.) no conteúdo das frases e palavras que eram escritas, possibilitaram a emergência de grafias significativas, pois estas passaram a refletir os significados que a criança desejou anotar. As constatações de Luria foram baseadas nas atividades desenvolvidas pelas crianças que não haviam aprendido as letras do alfabeto. Sendo assim, é importante esclarecer que as diferenciações na escrita produzida pelas crianças que participaram do nosso estudo não proporcionaram o surgimento de grafias expressivas. Acreditamos que isso decorre do fato de as crianças estarem inseridas em um processo de alfabetização escolar, em que as atividades de escrita requerem a utilização do sistema de escrita utilizado socialmente.

Conforme constatações de Ferreiro \& Teberosky (1989), no segundo nível de evolução da escrita, a hipótese fundamental da criança é que "para poder ler coisas diferentes (isto é, atribuir significados diferentes) deve baver uma diferença objetiva nas escritas" [grifo das autoras] (p. 189). As crianças acreditam que a escrita é legível quando possui quantidade e variedade de letras, ou seja, as crianças utilizam mais de duas letras e não repetem cadeias de letras para escrever significados diferentes. Como algumas crianças dispõem de um repertório reduzido de letras conhecidas, a única maneira de responder às exigências de legibilidade é por meio de variações de posição na ordem linear das grafias.

Os nossos resultados apontam que a natureza das diferenciações na escrita é qualitativa e quantitativa, conforme assinalam as autoras. Contudo, não podemos afirmar que estes eram critérios definidores da legibilidade do 
escrito, porque, apesar do esforço das crianças para distinguir os registros correspondentes às partes do texto e para variar as letras numa mesma cadeia, sabiam que a escrita não poderia ajudá-las a recordar os significados anotados. Por isso, nossa explicação é no sentido de que as crianças reproduziam aspectos formais da escrita convencional que estava sendo aprendida.

Nesse sentido, utilizavam os símbolos alfabéticos para representar o texto, mas a simbolização baseava-se na reprodução dos aspectos externos da escrita. Essa afirmação é confirmada pela observação de que alguns alunos, durante a pesquisa, na tentativa de reprodução desses aspectos, colocavam espaços em branco entre segmentos de letras utilizados para grafar as partes de um texto. Os segmentos separados pelos espaços em branco eram compostos por duas e por uma letra sem observar as diferenciações de natureza quantitativa. As diferenciações de natureza qualitativa, no entanto, eram mantidas. Dessa forma, a aparência da escrita era semelhante à escrita de um texto convencional. Observamos crianças que registraram todos os textos utilizando as separações na escrita e crianças que passaram a fazer uso desse expediente após alguns meses de trabalho na sala de aula. Essa maneira de reproduzir os aspectos formais da escrita, no início, não auxiliava a recordação do conteúdo do texto. Observemos a escrita da aluna Fernanda. Ela estava com 7 anos e 10 meses de idade quando produziu a escrita.

FERNANDA
TOANM DE FRMA
TAMANRN SA MNRAT
FRNTARPSI BE FMRATI
OATANMOSAMN EE NATDATA
OTANMNRPA N DE NTADBO
TOARATNM DE TLRPNTATANT
IAFELABDBCALRN BE NMTLATNTNEL
LANMFELADABACSRENM DE ATOAT




\section{Marcelo, marmelo, martelo}

Marcelo era um menino

que fazia perguntas.

Ele perguntou por que o seu nome era Marcelo.

- Por que o meu nome não pode ser marmelo?

- Porque esse é nome de fruta.

- Por que eu não posso chamar martelo?

- Porque é nome de ferramenta.

Fernanda separou os segmentos de letras utilizados para grafar cada enunciado do texto por espaços em branco e utilizou grafias com duas letras para compor os segmentos. Para formar as grafias com duas letras, utilizou sempre consoante/vogal: "de, sa, be, fe". Ela também diferenciou a escrita para registrar cada enunciado do texto. Assim, escreveu observando as diferenciações qualitativas, mas utilizou registros com duas letras e, dessa forma, diferentemente da escrita de Jéssica, Fernanda não observou o critério de quantidade mínima de letras para escrever cada segmento de grafias que compunha a escrita dos enunciados. A escrita da aluna afirma a análise que elaboramos: as crianças reproduzem as características externas da escrita. Inicialmente, essa reprodução pode ser traduzida por diferenciações baseadas nos eixos qualitativos e quantitativos. No entanto, à medida que avançam no processo de alfabetização escolar, aprendem que, na escrita, utilizamos palavras com duas e uma letra e, por isso, passam a utilizar também essas quantidades de letras para compor as grafias utilizadas para registrar os enunciados dos textos (é importante enfatizar que essa forma de registro só ocorreu porque as crianças registravam textos). Contudo, a reprodução da aparência externa da escrita não garantiu o surgimento de grafias expressivas e, portanto, não possibilitou que as crianças utilizassem a escrita para lembrar o texto. Quando as incentivamos a lembrar o texto com o apoio das grafias, rememoraram o texto demonstrando que as diferenciações baseadas no eixo qualitativo e a reprodução de grafias com duas letras não garantem o uso funcional da escrita.

\section{c) Relações entre as grafias e as unidades constituintes da linguagem oral}

A superação da atividade de escrita, baseada na reprodução dos aspectos formais, começou a ocorrer no momento em que as crianças passaram a organizar a escrita com base nas correspondências que 
estabeleciam entre o oral e o escrito. Em alguns casos, essas correspondências eram estabelecidas de modo manifesto, por meio da fala. Assim, num determinado momento, elas começaram, com base nos conhecimentos que estavam sendo aprendidos na sala de aula, a relacionar as letras registradas com as unidades constituintes da linguagem que eram pronunciadas. O início dessa compreensão não possibilitou que utilizassem a escrita como recurso mnemônico, mas permitiu que organizassem a escrita a partir dessa análise e não mais pelas características externas da escrita.

A escrita produzida com base nessa análise era, em alguns casos, aparentemente mais atrasada, porém, por detrás dessa aparência, havia um modo de operar a escrita que revelava o início de compreensão do seu simbolismo. De acordo com Vigotski, a escrita é um simbolismo de segunda ordem. "Isso significa que a linguagem escrita é constituída por um sistema de signos que designam os sons e as palavras da linguagem falada, os quais, por sua vez, são signos das relações das entidades reais" (1989a, p. 120). Vejamos a escrita produzida por Vanessa. Ela tinha 7 anos de idade.

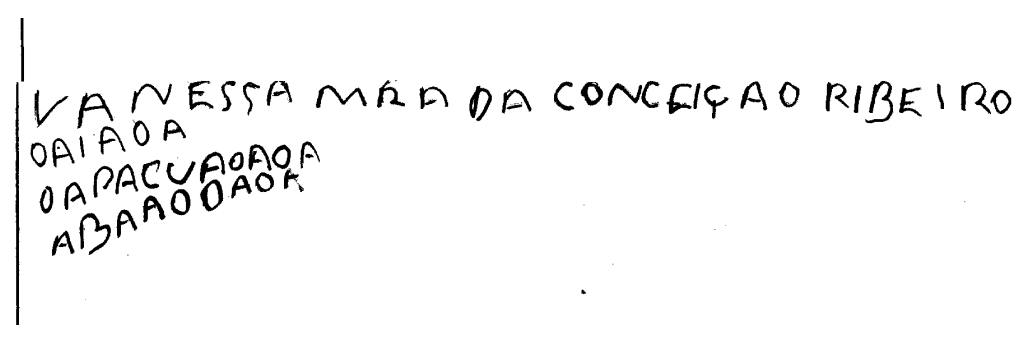

\section{Pularcorda}

Duas pessoas seguram a ponta da corda.

Depois, uma menina vai no meio para pular.

Como pode ser visto, a escrita dessa aluna difere nos aspectos formais da escrita anteriormente exemplificada. Ela usou as vogais "a, o e i" e as consoantes "p, c e b" para registrar o texto. No último segmento de grafias, escreveu as letras "o" e "a" seguidamente. Isso ocorreu, porque, diferentemente do que foi observado anteriormente, Vanessa analisava as unidades da linguagem oral e relacionava-as com a escrita. As unidades analisadas foram as sílabas e as palavras. Ela utilizou uma e duas letras para representar as sílabas e uma letra para representar uma palavra. Assim, a quantidade de letras registradas para cada frase era definida pelas relações que estabelecia 
verbalmente entre as unidades da linguagem oral e o escrito, e as letras que deveriam ser registradas eram definidas da mesma forma, por isso a nãopreocupação com a variação das letras numa mesma cadeia, pois utilizava, na maioria das situações, as vogais para representarem as sílabas.

Ao ser questionada se a escrita ajudaria a lembrar o conteúdo registrado, disse que não, "porque eu não me lembro das coisas que a tia falou”. Insistimos para que observasse o registro. Ficou olhando a escrita por algum tempo e começou a cantar "salada, saladinha”. Disse, então, que a brincadeira lembrava a música "porque eu canto isso quando vou pular corda”.

Assim, as tentativas de organização da escrita, a partir do oral, não possibilitaram o estabelecimento de uma relação funcional com os registros de modo que estes ajudassem a recordar o texto, mas a quantidade de letras utilizadas para escrever as frases que compunham o texto era definida pelas relações que estabelecia, no plano verbal, entre o oral e o escrito; da mesma forma, as letras utilizadas para escrever o texto foram definidas por essas relações.

A linguagem surge ao longo do desenvolvimento filogenético e do desenvolvimento ontogenético com função essencialmente comunicativa. As crianças, desde muito pequenas, utilizam a linguagem com essa finalidade, mas não conseguem pensar sobre ela, pois, conforme Delfior, isso "significa sair do seu uso comunicativo para prestar atenção nas formas da linguagem em si mesmas" [tradução nossa] (1998, p. 6). A escrita exige que as crianças comecem a tomar consciência da linguagem ou, como assinala Vigotski, requer que a criança passe "a tomar conhecimento da estrutura sonora de cada palavra, desmembrá-la e reproduzi-la, voluntariamente, em signos" [tradução nossa] (1993, p. 231). Dessa forma, escrever demanda uma ação analítica deliberada por parte da criança: exige que ela pense sobre a linguagem. Quando as crianças falam e mesmo os adultos, ainda segundo Delfior, normalmente o fazem sem "ter consciência de que estão utilizando palavras, de que estas são compostas por unidades menores" [tradução nossa] $(1998$, p. 6) e a aprendizagem da linguagem escrita requer a tomada de consciência de muitos aspectos do funcionamento lingüístico. A autora cita a analogia elaborada por Luria para explicar como as crianças são insensíveis à estrutura da linguagem:

(...) as palavras seriam como uma janela de cristal por meio da qual a criança olha o mundo que a rodeia, sem que essas palavras sejam objeto de sua consciência e sem suspeitar que tenham sua própria existência ou sua própria estrutura. (1988, p. 8) [Tradução nossa]. 
Porém, quando as crianças iniciam a alfabetização, passam a tomar consciência, a pensar/refletir sobre a linguagem oral e começam a desenvolver um conjunto de habilidades metalingüísticas, em particular a denominada de consciência fonológica. Segundo Delfior, o termo 'consciência fonológica' pode ser tomado em sentido estrito e amplo. No sentido estrito "se refere ao conhecimento que cada pessoa tem sobre os sons de sua própria língua" [tradução nossa] (1998, p. 11). No sentido amplo, ${ }^{4}$ trata "da habilidade de identificar, segmentar e manipular de forma intencional as unidades constituintes da linguagem oral” (p. 11) [tradução nossa].

Delfior assinala ainda que as discussões em torno da consciência fonológica residem em determinar quais são as unidades constituintes da linguagem oral:

\begin{abstract}
Alguns autores (Jiménez \& Ortiz, 1995) consideram como unidades fonológicas as palavras, as sílabas e os fonemas e defendem a existência de uma consciência léxica, uma consciência silábica e uma consciência fonêmica como partes da consciência fonológica; a maioria dos autores, no entanto, está de acordo que a consciência fonológica se refere às unidades que compõem as palavras, portanto, sílabas e fonemas (Gombert, 1990; Morais, Alegria \& Content, 1987) [...]. Outros, como Turnmer y Rohl (1991) só aceitam o fonema como objeto de análise da consciência fonológica. (1998, p. 12) [Tradução nossa].
\end{abstract}

Durante o trabalho realizado, vimos o surgimento da consciência fonológica: as crianças elaboravam, no plano verbal, a análise das unidades constituintes da linguagem oral e escreviam letras correspondentes às unidades analisadas. No início, a análise elaborada não possuía uma regularidade, pois as crianças pronunciavam enunciados inteiros do texto que eram ditados, pronunciavam palavras, pronunciavam sílabas e escreviam segmentos de letras correspondentes ao que era pronunciado. A quantidade de letras anotadas, também, não possuía uma regularidade. No entanto, tendo em vista o objetivo do estudo, mais importante do que analisar as regularidades nas relações entre o oral e o escrito e discutir quais são as unidades da linguagem oral que fazem parte da consciência fonológica, durante a fase inicial de alfabetização, é evidenciar que o fato de as crianças passarem a organizar a escrita não mais pela reprodução de seus atributos externos, mas pelas correspondências que elaboravam entre as unidades da linguagem oral e as letras anotadas, produz a superação da atividade gráfica baseada na reprodução das características externas da escrita. Elas começam a elaborar para si mesmas um conhecimento que a humanidade levou muito tempo para construir: as letras do alfabeto passam a representar a linguagem oral. 
Como as crianças manifestavam, durante o registro, as relações que estabeleciam entre as unidades da linguagem oral e os símbolos anotados no plano verbal, não podemos deixar de enfatizar a importância da linguagem nesse processo, pois converteu-se em meio de pensamento para as crianças e atuou como recurso que auxiliava a lembrança das letras que deveriam ser grafadas e, por isso, estava a serviço da atividade realizada. Observamos que a linguagem presente durante os registros era de dois tipos: comunicativa e egocêntrica. A primeira tinha por objetivo estabelecer contato com os pesquisadores para receber confirmação sobre as letras que deveriam ser utilizadas para escrever uma palavra e para confirmar onde deveriam ser colocados, na escrita, os espaços em branco. A segunda era para a própria criança e a auxiliava na lembrança das letras que deveriam ser escritas para representar uma determinada unidade da linguagem oral. As crianças repetiam oralmente essas unidades, o que levava à percepção das letras que deveriam ser grafadas.

Segundo as hipóteses de Vigotski, "a linguagem egocêntrica surge no curso de um processo social, quando as formas sociais de comportamento, as formas de cooperação coletiva, se deslocam para a esfera das funções individuais da criança” (1993, p. 57) [tradução nossa]. Para o autor, esse fenômeno de transição das formas sociais de atuação para a esfera da atividade psíquica é uma lei geral do desenvolvimento das funções psíquicas superiores. Assim, a linguagem egocêntrica traduz essa transição, está a serviço da orientação mental, da compreensão consciente. Ainda de acordo com Vigotski, Piaget não havia atribuído nenhuma função importante à linguagem egocêntrica. No entanto, concluiu que essa linguagem, que para Piaget, é um reflexo do pensamento egocêntrico e que desaparece próximo dos 7 anos, é fundamental, pois converte-se em um instrumento do pensamento. Como vimos, no exemplo apresentado anteriormente (Vanessa), as crianças analisavam, no plano verbal, as unidades que compõem a linguagem oral para, depois, escreverem os símbolos alfabéticos correspondentes às unidades analisadas. Dessa forma, começaram a elaborar para si mesmas essa relação, constituída no plano social, modificando completamente a orientação da atividade.

Vigotski diz ainda que o destino da linguagem egocêntrica é transformar-se em linguagem interna. Em termos gerais, "a linguagem egocêntrica surge da insuficiente individualização da linguagem, inicialmente social, de sua incipiente separação e diferenciação, de sua inespecificidade (...). A linguagem egocêntrica é um ponto situado em curva ascendente cujo ponto culminante está por chegar” (Vigotski, 1993, p. 314) [tradução nossa]. Assim, interpreta a progressiva diminuição do 
coeficiente da linguagem egocêntrica como "sintomas de progresso evolutivo; não é o fim, mas o nascimento de uma nova forma de linguagem" (p. 313) [grifo do autor]. Observamos que, em um determinado momento, as crianças deixavam de analisar as unidades da linguagem oral de maneira manifesta, por meio da linguagem egocêntrica. Contudo, conforme mostra Vigotski, elas não deixaram de realizar essa análise durante os registros, após a interiorização dessa linguagem, pois "interpretar a progressiva diminuição do coeficiente da linguagem egocêntrica como se fosse um sintoma de sua desaparição é supor que as crianças deixam de contar quando deixam de fazê-lo com os dedos e em voz alta e passam a fazê-lo mentalmente” (p. 312) [tradução nossa].

Acreditamos que uma análise profunda da linguagem egocêntrica poderá contribuir para que possamos compreender, no curso da aprendizagem da leitura e da escrita, como as crianças elaboram para si mesmas a análise das unidades da linguagem oral e, portanto, quais são as unidades fonológicas analisadas e como as representam por meio dos símbolos alfabéticos. No entanto, tendo em vista o objetivo deste estudo, é essencial enfatizar a importância dessa análise, que se desenvolve no plano verbal, e que, em algumas crianças, não se realiza de maneira manifesta na orientação da atividade, pois propiciou a dissolução da atividade gráfica baseada na reprodução das características externas da escrita. No início, entretanto, a análise das unidades da linguagem oral não possibilitou que as crianças se relacionassem com a escrita para lembrar o texto que motivou o registro. Elas continuavam a rememorar o texto sem o auxílio da escrita, ou não enunciavam o texto, porque argumentavam que a escrita não poderia ajudá-las.

\section{As crianças utilizavam a escrita como recurso mnemônico}

O surgimento de grafias que expressavam os significados anotados foi observado a partir de alguns fatores presentes no conteúdo dos textos elaborados oralmente pelas crianças. Nesse sentido, é importante lembrar que Luria (1988) mostrou que o aparecimento das diferenciações nos registros proporcionou a emergência da escrita simbólica, pois esta adquire "um significado funcional e começa graficamente a refletir o conteúdo que a criança deve anotar” (p. 181). Por sua vez, o surgimento de registros diferenciados resultou da introdução, no conteúdo das frases e palavras que deveriam ser registradas, de fatores, tais como: quantidade, forma, tamanho etc.

De modo semelhante, observamos que determinados fatores, presentes no conteúdo dos textos produzidos oralmente pelas crianças, 
propiciaram que a escrita passasse a expressar os significados anotados. No entanto, tais fatores não levaram a diferenciações das grafias. Eles provocaram, contrariamente, indiferenciações nas grafias utilizadas para escrever e foram essas escritas indiferenciadas que ajudaram a criança a lembrar o conteúdo que motivou o registro.

Dentre os fatores destacados por Luria (1988) que levam à diferenciação dos registros, o único observado, nas atividades realizadas pelas crianças que utilizavam letras do alfabeto para escrever, foi o de quantidade. Quando escreviam quantidades, estas eram representadas por meio de numerais ou por extenso. Ambas as representações auxiliavam a lembrança do conteúdo que motivou o registro ou de outro com o mesmo sentido. Contudo, as representações utilizadas pelas crianças envolvidas no estudo de Luria (1988), para as quantidades, eram diferentes daquelas que foram utilizadas pelas crianças que participaram do nosso estudo. No caso da pesquisa realizada por Luria, as crianças utilizavam representações que expressavam diretamente as quantidades. Por exemplo, Brina, ao escrever a frase "há duas árvores", traçou, primeiro, dois riscos e, em seguida, desenhou os galhos das árvores. No caso das nossas crianças, elas utilizaram os numerais ou palavras que estavam sendo aprendidos para representar as quantidades.

Da mesma forma, observamos que o registro de palavras que se repetiam ao longo do texto propiciou que as crianças passassem a representar essas palavras com uma mesma cadeia de letras, nos contextos em que eram escritas. Essa forma de representar as palavras que se repetiam possibilitou que as grafias passassem a expressar os seus significados, garantindo a lembrança da própria palavra, da parte do texto ligada a ela, de outra com o mesmo sentido ou de uma frase que era evocada no momento. Vejamos a escrita elaborada por Hugo, com 7 anos e 1 mês de idade.

$$
\begin{aligned}
& \text { Hugo Leon } \\
& \text { PAPABO LQAEA EPCOA } \\
& \text { BUALA HGIAE; , PAPATE } \\
& 1 \text { PaHa pata hqaea } 1 \text { PE HQA pia } \\
& \text { LQiC aIAIE BAPAHU, APEBUHE } \\
& C Q I C \text { AIAIE. BAPA } 1 \text { 1PÁOQQ } \\
& \text { LAPA ALIAI AIHA IPEHIAI } \\
& \text { PiA }
\end{aligned}
$$




\section{Pular corda}

Precisa de três pessoas

e muito mais gente: duas para bater

e uma para cantar. Bater a corda devagar e, depois, rápido e uma pessoa canta:

Senhoras e senhores, põem a mão no chão.

Senhores e senhores, pulem com um pé só.

Quando acaba a música, a criança tem que sair.

A criança escreveu como é a brincadeira de "pular corda”. Não há indícios, na escrita de Hugo, que garantam a legibilidade do texto. Apenas podemos observar que foram utilizados numerais para representar quantidades e que a criança não se preocupou em diferenciar os dois primeiros segmentos de letras escritos no início das quarta e quinta linhas. No entanto, a ilegibilidade é apenas aparente, pois essas escritas, que podem ser identificadas como reprodução de letras, orientaram a atividade de interpretação realizada por Hugo, ou seja, elas adquiriram um caráter expressivo.

Ao terminar o registro, pedimos a Hugo que lesse o texto produzido. Ele parou por alguns segundos e começou a leitura. Reproduziremos a escrita de Hugo para mostrar como ocorreu a interpretação do texto. Escrevemos em negrito as tentativas de leitura e numeramos cada seqüência de registros produzidos pelo aluno para facilitar a análise.

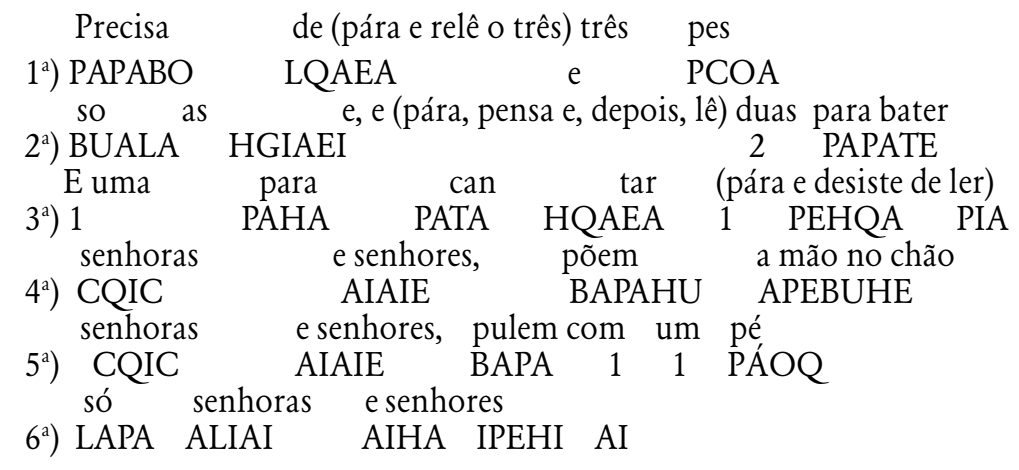

Hugo não leu o nome da brincadeira e os dois primeiros segmentos de letras que, durante a atividade de registro, correspondiam às palavras "pular corda" sendo incorporados à primeira frase. Ele começou a leitura pela primeira frase e esta pareceu estar memorizada. A utilização do título para garantir a leitura da primeira frase não é aleatório, pois ele esqueceu de registrar a palavra "precisa" e começou o 
registro por "três pessoas". Assim, fez corresponder os dois primeiros segmentos de letras à palavra "precisa" da primeira frase. Quando leu a palavra "de" para o número "três", parou um pouco, leu "três" e continuou corretamente lendo a palavra "pessoas" que terminou no segundo segmento de letras da linha seguinte. Novamente, ele parou diante do numeral 2, como se estivesse procurando recordar o conteúdo ligado a esse numeral e se lembrou da frase que foi escrita "e duas para bater". A terceira linha de registros é iniciada com o numeral 1 e Hugo não teve dúvidas, leu "e uma para cantar". Novamente, parou diante do registro do numeral 1, mas não conseguiu recuperar o conteúdo que estava ligado a ele e, então, continuou lendo a quarta linha: "senhoras e senhores, põem a mão no chão". Concluiu a leitura no final dessa mesma linha e iniciou a leitura da quinta linha: "senhoras e senhores, pulem com um pé só”.

Os dois primeiros segmentos de letras, no início das quarta e quinta linhas, foram compostos com as mesmas letras, o que demonstra que a criança sabia que, para escrever as mesmas palavras, são utilizadas as mesmas cadeias de letras; isso facilitou a lembrança dos versos. Na quinta linha, além dos segmentos utilizados para escrever "senhoras e senhores", o numeral "um” também possibilitou a leitura em "pulem com um pé só”. A leitura da frase que se inicia nessa linha é concluída no primeiro segmento de letras, na sexta linha. O primeiro segmento de letras correspondeu, na leitura efetuada pelo aluno, à palavra "só". A criança, então, continuou lendo: "senhoras e senhores", mas parou, pois percebeu que não era isso que estava escrito. Retomou a escrita da quinta linha e terminou a leitura: "pulem com um pé só”. Ficou pensativo por algum tempo até lembrar o conteúdo da última frase.

Assim, as presenças de quantidades e de palavras que se repetiam no texto propiciaram o surgimento de grafias indiferenciadas. Por sua vez, essas grafias levaram a criança a estabelecer uma relação funcional com a escrita e, portanto, possibilitaram a lembrança do texto que motivou o registro. As indiferenciações na escrita indicam que a criança compreendeu que uma mesma palavra deve ser sempre escrita com as mesmas letras, independentemente do contexto em que é escrita.

O terceiro fator que propiciou que as crianças utilizassem a escrita para lembrar o texto foi a presença, no texto, de palavras cuja grafia as crianças dominavam. À medida que as crianças participam das atividades de alfabetização, memorizam algumas palavras ou algumas letras que 
compõem as palavras que estão sendo estudadas. Quando uma dessas palavras se apresentava no texto, era escrita convencionalmente ou com as letras lembradas e estas possibilitavam a recordação dos enunciados do texto. Nos casos em que as crianças representavam as palavras com apenas algumas letras que compunham a sua escrita convencional, essas cadeias de letras eram utilizadas nos diferentes contextos em que eram escritas. Analisemos a escrita de Marianne, com 7 anos e 7 meses de idade, na época.

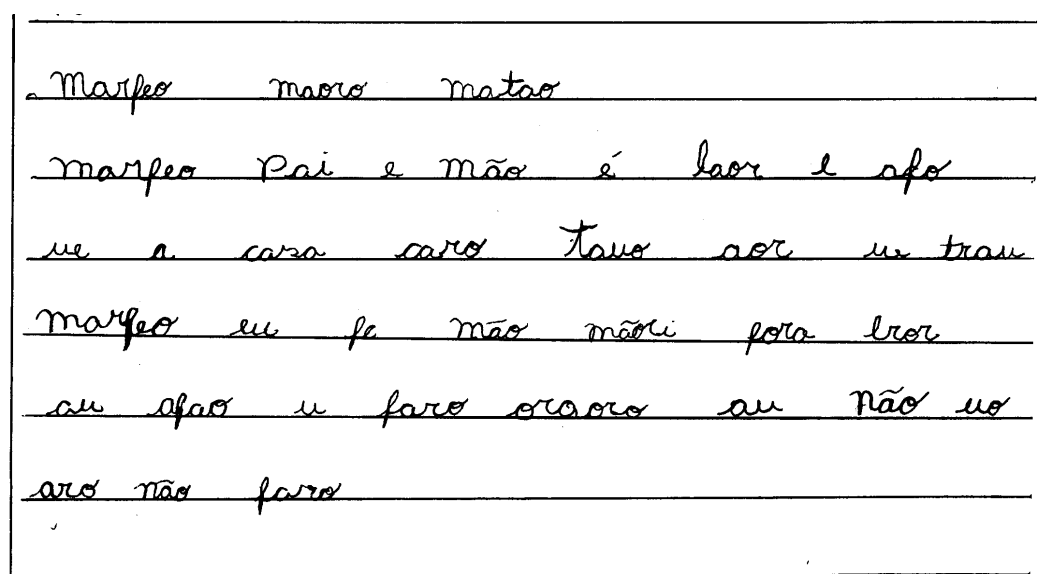

\section{Marcelo, marmelo, martelo}

Marcelo fazia muitas perguntas para o seu pai e a sua mãe. Ele colocava nomes diferentes nas coisas.

Um dia, a casa do cachorro pegou fogo, porque jogaram uma ponta de cigarro pela grade.

Marcelo perguntou para a sua mãe: - Mãe, por que a chuva cai?

Às vezes, os mais velhos respondiam às perguntas do Marcelo. Às vezes, não respondiam

porque não sabiam.

A aluna utilizou as letras "marfeo" para registrar, por três vezes, a palavra 'Marcelo'. Além disso, podemos interpretar as palavras 'pai', 'casa' e 'não'. Usou as letras “mão”, por três vezes, para representar a palavra 'mãe'. A interpretação que a aluna elaborou do texto é muito interessante. Para o segundo segmento de grafias, leu a primeira frase ("Marcelo fazia muitas perguntas para o seu pai e a sua mãe") apontando os espaços em branco, pois havia escrito apenas as palavras 
'Marcelo', 'pai’ e 'mãe'. A repetição das grafias utilizadas para representar as palavras 'Marcelo' e 'mãe' assim como o registro convencional das palavras 'pai' e 'não' contribuíram para que lembrasse um conteúdo próximo daquele que motivou a escrita. Nessa situação, ficou evidenciado que o registro de palavras cuja grafia a criança dominava, ou dominava algumas das letras que compõem a sua escrita convencional, possibilitou a lembrança dos enunciados do texto.

Resumindo, observamos que as crianças que participaram do estudo, no início, diferenciavam os registros, porque compreendiam a necessidade dessas distinções para registrar conteúdos diferentes. Essas diferenciações, no entanto, não proporcionaram o surgimento de grafias expressivas. Quando as crianças começaram a indiferenciar as cadeias de letras utilizadas para representar as palavras, estas adquiriram um caráter significativo, pois passaram a expressar os significados anotados.

\section{Considerações finais}

Como mencionamos no início deste artigo, o estudo que realizamos visou a contribuir para reflexões acerca do processo de alfabetização, por meio de uma análise que leva em conta os pressupostos teórico-metodológicos da Perspectiva Histórico-Cultural na Psicologia. Nesse sentido, partimos do princípio de que a linguagem escrita é um sistema de signos que serve de apoio às funções intelectuais e, por isso, priorizamos, nas atividades de registro dos textos, a função mnemônica da linguagem escrita.

As crianças, salvo algumas exceções, continuam a escrever, na escola, para reproduzir letras, o que leva à memorização das suas formas e dos correspondentes sonoros dessas formas. A linguagem escrita, conforme comenta Ferreiro (2001), por razões históricas, transformouse em um objeto de propriedade da escola, instituição responsável pela transmissão dos conhecimentos às novas gerações. Dessa forma, na escola quase sempre a escrita é tratada como atividade que tem um fim em si mesma, destituída das suas significações e das suas funções que a justificam como objeto cultural. Em outro estudo mostramos que as crianças consideram importante aprender a ler e a escrever para "passar para a segunda série, para fazer as tarefas que a professora escreve no quadro" etc.

Evidenciamos, nas atividades propostas às crianças durante o estudo, a linguagem escrita como uma produção humana e, portanto, 
como objeto cultural. Na Perspectiva Histórico-Cultural, "a cultura é, precisamente, o produto da vida social e da atividade social dos homens" (Vigotski, 1987, p. 162) [tradução nossa]. As crianças escreveram os textos para serem lidos por elas próprias e por outras pessoas. Escrever textos para si e para os outros é uma prática social e exige que as crianças utilizem uma das mais importantes produções humanas - o sistema de escrita elaborado ao longo da história social dos homens. A criação de signos e a sua utilização como recurso mnemônico são atividades que existem entre os homens e em nenhuma outra espécie animal.

Vigotski, ao discutir o desenvolvimento da escrita na ontogênese, assinala que "a escrita deve ter significado para as crianças (...) deve ser incorporada a uma tarefa necessária e relevante para a vida”. E termina dizendo: "Só então poderemos estar certos de que ela se desenvolverá não como um hábito de mãos e dedos, mas como uma forma nova e complexa de linguagem" (1989a, p. 133). Do ponto de vista pedagógico e social, a escrita só tem significado para a criança como produção humana que realiza funções social (comunicativa) e individual (escrever para si mesmo). De outra maneira, continuará a ser vista como a habilidade de associação entre respostas sonoras a estímulos gráficos, diminuída das significações que são, segundo Vigotski (1989a), o seu componente essencial.

\section{Recebido em setembro de 2001.}

Aprovado em dezembro de 2001.

\section{Notas}

1. Não sabemos até que ponto o termo 'substituição' é utilizado na tradução do texto de Luria (1988) correspondendo corretamente ao termo utilizado no trabalho original. Em um outro texto, Luria (1996) ao explicar os processos que levam ao desenvolvimento das formas culturais na criança, utiliza o termo 'superação'. Consideramos este termo, entendido no contexto do modelo teórico que orienta os estudos da Perspectiva HistóricoCultural na Psicologia, mais apropriado para explicar a dinâmica do desenvolvimento cultural. O termo 'superação' significa, na Língua Portuguesa, "ato ou efeito de superar". Superar, por sua vez, significa vencer, destruir, dominar. Porém, como nos lembra Vigotski (1987), o significado dessa expressão no alemão é, em primeiro lugar, eliminar, negar, mas ela significa também conservar. Dessa forma, o termo 'superação', no alemão, tem sentidos contraditórios e expressa adequadamente a dinâmica do desenvolvimento cultural nas crianças.

2. Nos exemplos que serão apresentados neste artigo, reproduziremos as escritas elaboradas pelas crianças durante o registro e, em seguida, o texto produzido oralmente na ordem em que foi escrito. 
3. Arbitrário, de acordo com Landsmann (1995), refere-se à relação entre símbolo e o simbolizado como oposta ao motivado. Desse modo, quando uma relação é arbitrária, só pode ser sustentada por uma convenção. A convenção é um agregado necessário à relação entre o símbolo e o simbolizado. Por sua vez, o convencional refere-se "a um acordo entre sujeitos (comunitário ou social) sobre a interpretação ou uso dos objetos ou símbolos de qualquer tipo".

4. Adotamos, no estudo realizado, o termo consciência fonológica no seu sentido amplo.

Referências bibliográficas

BREGUNCI, Maria das Graças de Castro. Construtivismo: Grandes e pequenas dúvidas. Intermédio - Cadernos Ceale, Belo Horizonte, 199 ?, ano $1, \mathrm{n}^{\underline{\mathrm{a}}} 1$.

DELFIOR, Sylvia. Conocimiento fonológico y lectura: el paso de las representaciones inconscientes a las conscientes. Revista Portuguesa de Pedagogia, Leitura, Universidade de Colômbia: Faculdade de Psicologia e de Ciências da Educação, 1998, ano XXXII, $\mathrm{n}^{\mathrm{a}}$ 1, p. 5-27.

DUARTE, Newton. $A$ individualidade para-si: Contribuição a uma teoria histórico-social da formação do indivíduo. São Paulo: Editores e Autores Associados, 1993.

FERREIRO, Emilia; TEBEROSKY, Ana. Psicogênese da língua escrita. Porto Alegre: Artes Médicas, 1989.

FERREIRO, Emilia. Cultura escrita e educação: Conversas de Emilia Ferreiro com José Antonio Castorina, Daniel Goldim e Rosa María Torres. Tradução de Ernani Rosa. Porto Alegre: ARTMED Editora, 2001.

LANDSMANN, Liliana Tolchinsky. Aprendizagem da linguagem escrita: Processos evolutivos e implicações didáticas. São Paulo: Ática, 1995.

LEONTIEV, Alexis. O desenvolvimento do psiquismo. Lisboa: Horizonte Universitário, 1978.

LURIA, Alexandr Romonovich. "A criança e o seu comportamento". In: Vigotski, Liev Semionovich; LuRIA, Alexandr Romonovich, Estudos sobre a bistória do comportamento: Símios, homem primitivo e criança. Porto Alegre: Artes Médicas, 1996. 
. "O desenvolvimento da escrita na criança". In: VIGotski, Liev Semionovich; LuRIA, Alexandr Romonovich; LeOnTIEv, Alexis, Linguagem, desenvolvimento e aprendizagem. $4^{\circ}$ ed. São Paulo: Icone, 1988.

VIGOTSKI, Liev Semionovich. Formação social da mente. São Paulo: Martins Fontes, 1989a.

. A bistoria del desarrollo da las funciones psíquicas superiores. Cuba: Editorial Científico Técnica, 1987.

. Obras escogidas. Tomo II, 1993. 